\title{
Use of gabapentin in management of postoperative pain after crosslinking
}

\author{
Uso da gabapentina no manejo da dor pós-operatória do crosslinking
}

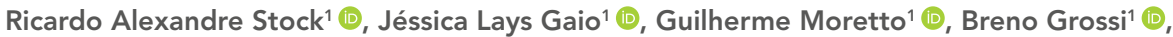
Rafael André Mergener ${ }^{1}$ (D), Elcio Luiz Bonamigo ${ }^{1}$ (i)

Medical School, Universidade do Oeste de Santa Catarina, Joaçaba, SC, Brazil

Keywords:

Keratoconus; Gabapentin; Pain; Pain, postoperative; Postoperative care

Descritores: Ceratocone; Gabapentina; Dor; Dor pós-operatória; Cuidados pós-operatórios

Received on: Oct. 21, 2020

Accepted on: Jan. 01,2021

Corresponding author: Ricardo Alexandre Stock Belotto Stock Centro Oftalmológico Rua Rio Branco, 589 - Centro CEP: 89600-000 - Joaçaba, SC, Brazil E-mail ricardostockreal@gmail.com

Institution: Medical School, Universidade do Oeste de Santa Catarina, Joaçaba, SC, Brazil.

Conflict of interest: no conflict of interest. Financial support:
the authors received no financial support for this work.

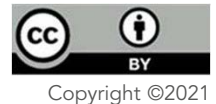

\section{ABSTRACT}

Objective: The objective was to evaluate the efficacy of gabapentin in the management of neuropathic pain in patients with keratoconus, who were treated with fast (10 minutes) epi-off corneal crosslinking (CXL).

Methods: This was a prospective, double-blind, randomized study. The sample comprised patients with bilateral progressive keratoconus, aged 12 years or older, who underwent a bilateral epi-off corneal CXL (fast - 10 minutes) procedure. One group was given placebo orally, and the other group received gabapentin $600 \mathrm{mg}$ orally, both preoperatively. The visual analogue scale (VAS) was applied to record postoperative pain up to 48 hours after procedure. The study was conducted at the Belotto Stock Centro Oftalmológico, in the city of Joaçaba, Santa Catarina, Brazil, from June 2018 to September 2019.

Results: At no point in the study significant differences were observed between groups, in terms of pain intensity measured by means of the VAS questionnaire, or of opioid use ( $\left.\mathrm{Paco}{ }^{\circledR}\right)$, though opioid consumption was $21 \%$ lower in the group receiving gabapentin.

Conclusion: We concluded gabapentin has no efficacy in postoperative pain control after epi-off corneal CXL (fast - 10 minutes). Although there was no statistically significant difference, the group that received gabapentin suffered less pain, resulting in lower opioid consumption.

UTN number: U1111-1256-0330.

\section{RESUMO}

Objetivo: Avaliar a eficácia do uso da gabapentina no manejo da dor neuropática em pacientes portadores de ceratocone submetidos ao tratamento de crosslinking corneano epi-off fast de 10 minutos.

Métodos: Tratou-se de pesquisa prospectiva, duplo-cega, randomizada. A amostra foi composta de pacientes com ceratocone progressivo bilateral, a partir dos 12 anos de idade, submetidos ao procedimento de crosslinking corneano acelerado epi-off fast de 10 minutos bilateral. Um grupo recebeu placebo via oral e o outro, gabapentina $600 \mathrm{mg}$, via oral, ambos no pré-operatório. A Escala Visual Analógica foi aplicada para registrar a dor pós-operatória até 48 horas após o procedimento. A pesquisa foi realizada no período de junho de 2018 a setembro de 2019 em um centro oftalmológico.

Resultados: Não foram observadas diferenças estatísticas significativas para ambos os grupos, tanto na intensidade da dor medida pela Escala Visual Analógica, como na redução do uso do opioide (Paco®), em qualquer horário analisado durante um período de 48 horas. No entanto, houve redução de $21 \%$ no consumo de opioides pelo grupo que fez uso da gabapentina.

Conclusão: A gabapentina não demonstrou eficácia no controle da dor no pós-operatório do crosslinking corneano epi-off fast de 10 minutos. No entanto, observou-se que, mesmo não havendo diferença estatisticamente significativa, houve diminuição da dor no grupo em que foi usada a gabapentina, resultando na redução do consumo de opioides.

Número UTN: U1111-1256-0330. 


\section{INTRODUCTION}

Neuropathic pain is common after some surgical procedures, such as crosslinking to treat keratoconus, and, in most cases, patients refer an intense and disabling pain. Although not vascularized, the cornea is richly innervated and lesions to or exposure of nerves during surgery can cause extreme pain in the postoperative period.

The cornea is densely innervated by a network of nerve endings of the long ciliary nerves, which originate from the ophthalmic branch of the trigeminal nerve (cranial nerve V), and are located mainly in the epithelial layer, making it one of the most sensitive tissues of the body. ${ }^{(1)}$ The nerve fibers penetrate the cornea radially through the deep peripheral stroma, and then emerge anteriorly, forming a terminal subepithelial plexus. Most sensory nerve receptors on the cornea are nociceptors, and lesions in individual epithelial cells may be sufficient to trigger intense pain. ${ }^{(2)}$

The only proven treatment to interrupt keratoconus progression is corneal collagen crosslinking (CXL), (3) which was introduced by Eberhard Spoesi and Theo Seiler, in 1990. ${ }^{(4)}$ The procedure was first described in 2003, by Wollensak et al., ${ }^{(5)}$ who used riboflavin (vitamin B2) and ultraviolet A (UVA) irradiation to promote CXL in corneal collagen fibers, rendering a therapeutic method to manage progressive keratoconus and other ectatic corneal diseases, such as post-laser in-situ keratomileusis ectasia, and pellucida marginal degeneration. Thus, CXL is a minimally invasive therapeutic procedure aiming to block the progression of keratoconus, preventing or delaying the need for corneal transplantation. However, CXL surgery makes de-epithelialization of the cornea, leaving the nerves exposed, and causing intense neuropathic pain, which is reported by many patients as the worst experience of their lives.

Based on several studies that have reported efficacy in the management of neuropathic pain gabapentin, especially at a dose of $600 \mathrm{mg},{ }^{(6,7)}$ administered before or after surgery on other organs, and on the observation of decreased opioid use in gabapentin users, as well as the lack of available options for pain control after corneal CXL, this study sought an alternative to expand the therapeutic options to improve quality of life of patients and, consequently, the surgical outcome. Therefore, the efficacy of gabapentin compared to placebo in management of acute neuropathic pain after CXL was investigated using a visual pain scale and observation of opioid consumption.

\section{METHODS}

This was a prospective, double-blind, randomized study. The sample consisted of patients with progressive keratoconus aged 12 years or older, with no contraindications to the procedure, who underwent accelerated epi-off CXL (fast-10 minutes). Twelve patients (six men) were randomly selected to participate in this study, totalling 24 eyes. All were submitted to epi-off CXL (fast - 10 minutes) in both eyes. In one group (Placebo Group), two placebo capsules were given orally, and in the other (Gabapentin Group), two capsules containing $300 \mathrm{mg}$ gabapentin were given (Gabapentin, Sandoz, India), totalling 600 mg orally.

Medication (placebo or gabapentin) was used in the preoperative period ( 2 hours before) in both groups. As a tool to assess postoperative pain, the patients rated their pain on the Wong-Baker faces scale or numeric Visual Analogue Scale (VAS) after the surgical procedure, and the number of opioid units taken was counted. The study was conducted from June 2018 to September 2019 at the Centro Oftalmológico Belotto Stock, located in Joaçaba (SC), Brazil.

The surgical technique was the Fast $9 \mathrm{~mW} / \mathrm{cm}^{2}$ protocol with a UVA application time of 10 minutes. Thirty minutes before the initiating the procedure, $1 \%$ pilocarpine eye drops (Pilocarpina, Allergan, Guarulhos, SP, Brazil) were instilled twice. In the operating room, under aseptic conditions and patient in supine position, 5\% povidone iodine and 1\% tetracaine hydrochloride with 0.1\% phenylephrine hydrochloride (Anestésico, Allergan, Guarulhos, SP, Brazil) were applied 5 minutes before the procedure.

Next, disposable sterile fields were placed, and a eyelid speculum was adapted to keep the eye open. Then, the central $9 \mathrm{~mm}$ of the cornea was stained with a circular marker, and the central $8 \mathrm{~mm}$ of the epithelium of the cornea was removed by debridement, using $1 \%$ riboflavin, 400-osm application with 1\% methylcellulose every 3 minutes, for 30 minutes. The cornea was then irradiated with UVA light (Opto Xlink) at a wavelength of 370 $\mathrm{nm}$ and an irradiance of $9 \mathrm{~mW} / \mathrm{cm}^{2}$ (surface dose of $5.4 \mathrm{~J} /$ $\left.\mathrm{cm}^{2}\right)$, at a distance of $4.5 \mathrm{~cm}$, for 10 minutes. During irradiation, riboflavin droplets were applied to the cornea every 5 minutes, along with topical anaesthesia (1\% tetracaine hydrochloride with $0.1 \%$ phenylephrine hydrochloride) if necessary, for pain. At the end of the radiation, a bandage soft contact lens was tailored, which was maintained until complete corneal re-epithelialization.

To analyze patient's pain, a single blinded investigator applied the questionnaire containing the numeric VAS, in 
the postoperative period, and guided how this questionnaire should be filled in at the patient's home. The patient marked the VAS 2, 4, 6, 8, 24, and 48 hours after the procedure. All patients were instructed to use a narcotic analgesic if postoperative pain was reported, and $500 \mathrm{mg}$ paracetamol + codeine $30 \mathrm{mg}\left(\mathrm{Paco}{ }^{\circ}\right)$ was prescribed, one tablet orally, every 4 hours, if necessary. All patients participating in the study were asked to fill in the VAS that was delivered after hospital discharge, and record the drug intake. The procedures were performed after patients signing the informed consent form.

Data were input in a Microsoft Excel table and analyzed using Biostat 5.0 software. The chi-squared test was used for statistical analysis, with a significance level of $5 \%$ for interpretation. The project was posted on the Plataforma Brasil, submitted for analysis by the Research Ethics Committee of the Universidade do Oeste de Santa Catarina (Unoesc), and was approved under number 2,931,506.

\section{RESULTS}

The mean age of patients was 20.5 years (range 13-31 years). The mean pain on the numeric VAS, in patients subjected to fast CXL, is shown in Figure 1, which compares the Placebo Group with the Gabapentin Group at the observed postoperative intervals. Although 2, 4, 8, 24 and 48 hours were the times at which the highest average pain was observed in patients who used placebo, there were no statistically significant differences in the pain scale between Placebo and Gabapentin Groups, at any point of the study. The statistical comparisons (p-values) yielded the following results: in the immediate postoperative period, $\mathrm{p}=0.1425$; after 2 hours, $\mathrm{p}=0.6224$; after 4 hours, $\mathrm{p}=0.6679$; after 6 hours, $\mathrm{p}=0.9471$; after 8 hours, $\mathrm{p}=0.4880$; after 24 hours, $\mathrm{p}=0.2989$ and; after 48 hours, $\mathrm{p}=0.4745$.

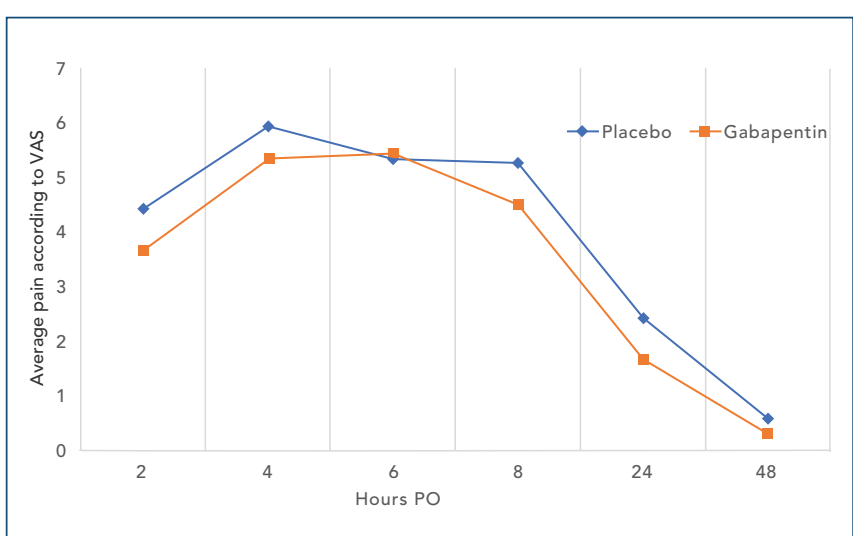

Figure 1. Average pain according to the Visual Analogue Scale 2, 4, 6, 8, 24, and 48 hours after corneal crosslinking.
The number of Paco tablets (codeine $30 \mathrm{mg}+$ paracetamol $500 \mathrm{mg}$ ) used by patients for pain relief was also used as a method to assess pain intensity. Patients who were given placebo (Placebo Group) consumed 27 tablets, and those who were given gabapentin (Gabapentin Group) consumed 22 tablets ( $21 \%$ less) $(\mathrm{p}=0.196)$, as shown in Table 1 and Figure 2.

Table 1. Number of $\mathrm{Paco}^{\circledR}$ tablets used by Placebo Group and Gabapentin Group

\begin{tabular}{lcc} 
Hours & $\begin{array}{c}\text { Use of Paco }{ }^{\circledR} \text { (tablets) - } \\
\text { Placebo Group }\end{array}$ & $\begin{array}{c}\text { Use of Paco }{ }^{\circledR} \text { (tablets) } \\
\text { Gabapentin Group }\end{array}$ \\
\hline 2 & 8 & 4 \\
4 & 2 & 2 \\
6 & 4 & 1 \\
8 & 4 & 5 \\
24 & 7 & 8 \\
48 & 2 & 2 \\
\hline & Total $=27$ tablets & Total $=22$ tablets
\end{tabular}

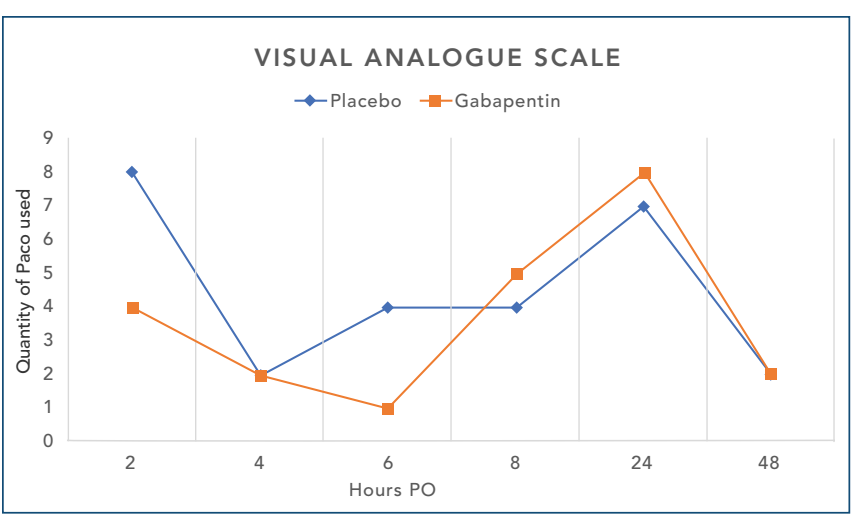

Figure 2. Number of $\mathrm{Paco}^{\circledR}$ tablets used per hour by patients in the Placebo Group and the Gabapentin Group.

\section{DISCUSSION}

The VAS showed no significant difference between Placebo Group and Gabapentin Group, who were given a 600-mg preoperative dose of the drug to control neuropathic pain, among patients undergoing treatment with accelerated epi-off CXL (fast - 10 minutes). There was lower opioid consumption by Gabapentin Group (27 versus 22 tablets), a decrease by 21\%, although the difference was not significant.

One study showed the perioperative use of the anticonvulsant gabapentin was useful to reduce postoperative neuropathic pain, owing to its cellular and molecular action. ${ }^{\left({ }^{8}\right)}$ Clinical trials of gabapentin administration in humans in the perioperative period are based on the fact that gabapentin can reduce acute postoperative pain and consumption of opiates. For instance, in a study on low back pain, gabapentin was given in the preoperative period and immediately after incision, resulting in lower 
numeric VAS score and lower use of fentanyl, as compared to the group using placebo..$^{(9)}$

Studies testing gabapentin have used doses ranging from 300 to $1,800 \mathrm{mg}$, administered as single preoperative dose or multiple perioperative doses. According to Clarke et al.,10) different forms of use resulted in similar improvements in pain control and relief of chronic pain. Ajori et al. ${ }^{(6)}$ demonstrated gabapentin $600 \mathrm{mg}$ given preoperatively provided a significant reduction in postoperative abdominal hysterectomy pain, for 24 hours. In otolaryngology studies investigating the use of gabapentin for acute postoperative pain, 600 to 1,200mg were administered in a single preoperative dose, achieving a reduction in the use of pain medication for up to 24 hours in patients undergoing tonsillectomy, thyroidectomy, or sinus surgery.(6) A review study on pain after open or endoscopic surgeries found the consumption of morphine, measured by standard mean difference, was effective at the preoperative dosage of 1,200 $\mathrm{mg}$, reaching a reduction index of -1.6 or better, in all five studies included, while only one of seven studies that used 6oomg presented a similar result. ${ }^{(11)}$

Gabapentin for pain reduction at several postoperative times after CXL was evaluated in only one study, conducted by Serna-Ojeda et al., ${ }^{(12)}$ in June 2019, when it was compared with ketorolac (Toragesic) for management of postoperative pain. The authors concluded both drugs had similar efficacy, with no statistically significant difference in the numeric VAS, as observed in our study.

The only proven treatment that interrupts the progression of keratoconus is corneal CXL. In case of progression visual correction with glasses or contact lenses worsens, leading to decreased vision, corneal scars, and the need for corneal transplants in $10 \%$ to $20 \%$ of cases, which are avoidable when performing CXL. ${ }^{(13,14)}$

Postoperative pain after CXL begins with epithelial rupture in epi-off procedures that expose nerve endings, and induce apoptosis and necrosis of epithelial cells. ${ }^{(15)}$ Together, these factors initiate an inflammatory cascade, in which different inflammatory cytokines stimulate nerve endings sensitive to chemical stimuli, and inflammatory mediators activate ion channels in the nerve membrane, a process that continues until the epithelium heals. ${ }^{(16)}$

Gabapentin was the drug of choice because it reduces hyperexcitability induced by neuron injury in the posterior horn, which is responsible for central sensitization, suggesting the mechanism of antihyperalgesic action may be the result of the postsynaptic binding of gabapentin to the $\alpha_{2}-\delta$ subunits of the calcium-dependent channels of dorsal horn neurons, thus decreasing release of neurotransmitters. ${ }^{(17)}$
In ophthalmology, most postoperative pain studies are on refractive surgeries, and in the United States, ketorolac and diclofenac are the non-steroidal anti-inflammatory drugs (NSAIDs) of choice. ${ }^{(18)}$ There is evidence that NSAIDs administered topically before refractive surgery are efficient because they decrease intensity of postoperative pain and photophobia. ${ }^{(17)}$ Instillation of a drop of $0.1 \%$ diclofenac and 0.5\% ketorolac 30 minutes before starting the CXL procedure is recommended to minimize postoperative pain. ${ }^{(19)}$

Studies on pain or discomfort in the postoperative period of CXL are very scarce, ${ }^{(2)}$ especially investigations using gabapentin, although pain is very intense, particularly during the first 24 hours. This usually occurs due to ablation of the corneal epithelial surface, resulting in exposure of the nerves and consequent inflammation. (20) Postoperative pain after CXL can be very intense, especially in the first 3 days, even with an efficient pain control. ${ }^{(2)}$ Therefore improved pain control methods are needed, ${ }^{(20,21)}$ since analgesia helps optimizing patient recovery, maintaining visual functions, and minimizing complications..

Our study had some limitations. First, the sample size was small and gabapentin was given exclusively at a dose of $600 \mathrm{mg}$. Second, only pain was analyzed and other symptoms, such as photosensitivity and discomfort, were not considered. Finally, pain perception has a subjective character and interpersonal variability, and their measurement can be affected by factors not evaluated in this study.

\section{CONCLUSION}

Gabapentin did not show efficacy in postoperative pain control after epi-off corneal crosslinking (fast - 10 minutes) compared to placebo. Even though there was no statistically significant difference, there was a little decrease in pain in the Gabapentin Group, resulting in reduced use of opioids. Hence, gabapentin may be an alternative treatment with fewer side effects. When combined with other drugs, gabapentin may promote pain relief and improve patient's quality of life in the postoperative period.

Further studies are required to confirm the efficacy of gabapentin in treatment of postoperative pain after corneal crosslinking, especially testing higher doses, in a larger sample.

\section{ACKNOWLEDGMENTS}

Not applicable. 


\section{REFERENCES}

1. Murphy PJ, Patel S, Kong N, Ryder RE, Marshall J. Noninvasive assessment of corneal sensitivity in young and elderly diabetic and nondiabetic subjects. Invest Ophthalmol Vis Sci. 2004;45(6):1737-42.

2. Ghanem VC, Ghanem RC, de Oliveira R. Postoperative pain after corneal collagen cross-linking. Cornea. 2013;32(1):20-4.

3. Asri D, Touboul D, Fournié P, Malet F, Garra C, Gallois A, et al. Corneal collagen crosslinking in progressive keratoconus: multicenter results from the French National Reference Center for Keratoconus. J Cataract Refract Surg. 2011;37(12):2137-43.

4. Khan MD, Ameen SS, Niazi OI, Araeen MA, Naz MA, Fayyaz M. Preliminary results of UV? A riboflavin crosslinking in progressive cases of keratoconus, in Pakistani population. Pak J Ophthalmol. 2011;27(1):21-6.

5. Wollensak G, Spoerl E, Seiler T. Riboflavin/ultraviolet-a-induced collagen crosslinking for the treatment of keratoconus. Am J Ophthalmol. 2003;135(5):620-7.

6. Ajori L, Nazari L, Mazloomfard MM, Amiri Z. Effects of gabapentin on postoperative pain, nausea and vomiting after abdominal hysterectomy: a double blind randomized clinical trial. Arch Gynecol Obstet. 2012;285(3):677-82.

7. Lee JH, Lee HK, Chun NH, So Y, Lim CY. The prophylactic effects of gabapentin on postoperative sore throat after thyroid surgery. Korean $\mathrm{J}$ Anesthesiol. 2013;64(2):138-42.

8. Maneuf YP, Gonzalez MI, Sutton KS, Chung FZ, Pinnock RD, Lee K. Cellular and molecular action of the putative GABA-mimetic, gabapentin. Cell Mol Life Sci. 2003;60(4):742-50.

9. Pandey CK, Navkar DV, Giri PJ, Raza M, Behari S, Singh RB, et al. Evaluation of the optimal preemptive dose of gabapentin for postoperative pain relief after lumbar diskectomy: a randomized, double-blind, placebo-controlled study. J Neurosurg Anesthesiol. 2005;17(2):65-8.

10. Clarke H, Poon M, Weinrib A, Katznelson R, Wentlandt K, Katz J. Preventive analgesia and novel strategies for the prevention of chronic post-surgical pain. Drugs. 2015;75(4):339-51.
11. Arumugam S, Lau CS, Chamberlain RS. Use of preoperative gabapentin significantly reduces postoperative opioid consumption: a meta-analysis. J Pain Res. 2016;9:631-40.

12. Serna-Ojeda JC, Santana-Cruz O, Quiroz-Casian N, González-Mendoza E, Mercado-Orozco JL, Navas A, et al. Pain management in corneal collagen crosslinking for keratoconus: a comparative case series. J Ocul Pharmacol Ther. 2019;35(6):325-30.

13. Godefrooij DA, Gans R, Imhof SM, Wisse RP. Nationwide reduction in the number of corneal transplantations for keratoconus following the implementation of cross-linking. Acta Ophthalmol. 2016;94(7):675-8.

14. Randleman JB, Khandelwal SS, Hafezi F. Corneal cross-linking. Surv Ophthalmol. 2015;60(6):509-23.

15. Hirji N, Sykakis E, Lam FC, Petrarca R, Hamada S, Lake D. Corneal collagen crosslinking for keratoconus or corneal ectasia without epithelial debridement. Eye (Lond). 2015;29(6):764-8.

16. Garcia R, de Andrade DC, Teixeira MJ, Nozaki SS, Bechara SJ. Mechanisms of corneal pain and implications for postoperative pain after laser correction of refractive errors. Clin J Pain. 2016;32(5):450-8.

17. Gidal BE, Billington R. New and emerging treatment options for neuropathic pain. Am J Manag Care. 2006;12(9 Suppl):S269-78.

18. Razmju H, Khalilian A, Peyman A, Abtahi SH, Abtahi MA, Akbari M, et al. Preoperative topical diclofenac and ketorolac in prevention of pain and discomfort following photorefractive keratectomy: a randomized double-masked placebo-controlled clinical trial. Int J Prev Med. 2012;3 Suppl 1:S199-206.

19. Hong JP, Nam SM, Im CY, Yoon S, Kim TI, Kim EK, et al. Comparison of analgesic effect of preoperative topical diclofenac and ketorolac on postoperative pain after photorefractive keratectomy. J Cataract Refract Surg. 2014;40(10):1689-96.

20. Krueger RR. Introduction to commercially approved wavefront-guided customization: third year in review. J Refract Surg. 2005;21(6):S767-8.

21. Townsend M, Liou T, Kallogjeri D, Schoer M, Scott-Wittenborn N, Lindburg $M$, et al. Effect of perioperative gabapentin use on postsurgical pain in patients undergoing head and neck mucosal surgery: a randomized clinical trial. JAMA Otolaryngol Head Neck Surg. 2018;144(11):959-66. 